\title{
AVERMECTIN PRODUCTION BY SOLID STATE FERMENTATION-A NOVEL APPROACH
}

\author{
SHADAB KHANa ${ }^{*}$, PUSHPENDRA AWADHIYAa, SHRIDHAR PATILa, TUSHAR BANERJEE ${ }^{a}$
}

aApplied Microbiology Laboratory, School of Life Sciences, Devi Ahilya Vishwavidyalaya, Takshashila Campus, Khandwa Road, Indore, Madhya Pradesh-452001, India

Email: shadab15khan@gmail.com

Received: 03 Jun 2017 Revised and Accepted: 31 Aug 2017

\begin{abstract}
Objective: The present study was carried out to evaluate SSF process for the production of avermectin by Streptomyces avermitilis NRRL 8165 using easily available grains, millets and some agricultural by-product.
\end{abstract}

Methods: Various substrates were screened for their ability to support avermectin production. Different parameters to maximize the yield of avermectin by $S$. avermitilis NRRL 8165 under SSF were optimized by conventional one factor at a time approach and parameters optimized earlier were adopted for the subsequent study.

Results: Sorghum seeds used as solid substrate supported maximum growth and total avermectin production (4.6 mg g-1 dry substrate). The optimum values for maximum avermectin production were: moistening medium containing g l-1 $\mathrm{KH}_{2} \mathrm{PO}_{4} 1 ; \mathrm{MgSO}_{4} .7 \mathrm{H}_{2} \mathrm{O} 0.4$, inoculum size $20 \%$ (24 $\mathrm{h}$ old culture in yeast extract-malt extract dextrose medium) v/w of initial dry substrate, substrate particle size 0.5 to 4 mm, incubation temperature $28{ }^{\circ} \mathrm{C}$, initial moisture level $105 \%$, incubation period of $15 \mathrm{~d}, 8 \% \mathrm{w} / \mathrm{w}$ sucrose and $5 \%$ w/w soyameal. The avermectin yield with optimized fermentation condition was $5.8 \mathrm{mg} \mathrm{g}^{-1}$ dry substrate which is 1.3 fold higher as compared to non-optimized condition.

Conclusion: Avermectin produced by $S$. avermitilis are widely used as an anthelmintic agent in the medical, veterinary and agricultural applications. In comparison with submerged fermentation, SSF can become an alternative cost-effective method for the production of avermectin. This report demonstrates the feasibility of employing agro-based substrate, that could reduce antibiotics production cost.

Keywords: Solid state fermentation, Avermectin, Streptomyces avermitilis, Sorghum, Optimization

(C) 2017 The Authors. Published by Innovare Academic Sciences Pvt Ltd. This is an open access article under the CC BY license (http://creativecommons.org/licenses/by/4.0/) DOI: http://dx.doi.org/10.22159/ijpps.2017v9i10.20470

\section{INTRODUCTION}

Avermectin produced by Streptomyces avermitilis are 16-membered macrocyclic polyketides antibiotics [1]. It has broad-spectrum anthelmintic activity against nematodes and arthropod parasites [2]. Recent testing revealed that avermectin also have potent antibacterial activity against various multidrug-resistant strains of Mycobacterium tuberculosis [3]. Presently, avermectin are exclusively produced by submerged fermentation (SmF) using mutants of $S$. avermitilis. Gao et al. [4] reported $5.1 \mathrm{~g} \mathrm{l}^{-1}$ avermectin $\mathrm{B}_{1 \text { a }}$ productions using a mutated organism $S$. avermitilis $14-12 \mathrm{~A}$ at flask scale. These mutants are produced by various time and labourintensive methods [5]. Chromosomal instability has also been reported in $S$. avermitilis, which is higher in mutant strains as compared to wild strain [6]. Novak et al. [7] reported instability in avermectin production, sporulation and pigmentation of $S$. avermitilis $\mathrm{C}-18 / 6$ strain during subculturing. However, $\mathrm{SmF}$ has various disadvantages including a high volume of polluting effluent production, high volume and cost technology, high energy consumption, high risk of contamination, costly raw material, expensive bioreactor and complex downstream processing $[8,9]$.

Solid-state fermentation (SSF) has been developed as a microbial culture with solid substrates or impregnated inert support. SSF process is believed to mimic natural environment and encourage the microorganism to work at its best for the production of the product [9]. Compared with SmF, SSF has various advantages, including less water requirement, less energy, less production cost, less wastewater, simpler equipment, reduced volume of production media and reduced contamination risk [10]. SSF has very high potential for the production of secondary metabolites. Moreover, some secondary metabolites can only be produced under SSF conditions, like coniosetin, acremonidins A-E, pyrrocidienes A and B [11]. Several studies have been published recently on the production of secondary metabolites in SSF from Streptomyces like cephamycin C, tetracycline, oxytetracycline, actinorhodin and methylenomycin. SSF has been proved to be more efficient for production of cephamycin C, tetracycline and oxytetracycline as compared to $\mathrm{SmF}$ [9].

The microbial metabolites biosynthesis greatly influence by physiological, nutritional and microbial parameters of fermentation process. To improve production of desire metabolite, optimization of these parameters were critically important [12]. Literature survey indicated that this organism has not been so far evaluated for the production of avermectin under SSF. The present study was carried out to evaluate SSF process for production of avermectin by $S$. avermitilis NRRL 8165 using easily available grains, millets and some agricultural byproduct.

\section{MATERIALS AND METHODS}

\section{Chemicals}

An authentic sample of avermectin (abamectin, containing $80 \%$ avermectin $\mathrm{B}_{1 \mathrm{a}}$ ) was procured from Baoding Jaihe Fermentation Co., Baoding, PRC. All other chemicals and solvents used were of AR grade except methanol (HPLC grade).

\section{Microorganism}

Streptomyces avermitilis NRRL 8165 a wild-type avermectin producer was used in the study and procured from northern regional research Laboratory, Peoria, Illinois, USA. It was stored in $20 \%$ glycerol at $-80{ }^{\circ} \mathrm{C}$ for long-term preservation. The working cultures of the microorganism were prepared by cultivation on yeast extract-malt extract glucose (YMG) agar and incubated at $28^{\circ} \mathrm{C}$ until sporulation occurred (4-6 d) and slants were stored at $4{ }^{\circ} \mathrm{C}$.

\section{Solid state fermentation}

All substrates like wheat bran, wheat rawa (wheat grains broken into small pieces of the size of 0.1-1 mm), seeds of sorghum, amaranth, pearl millet, barley, maize, potato (fresh) and sawdust were obtained locally. Except for wheat bran and wheat rawa, other substrates were 
lightly crushed and passed through 40 and 10 mesh sieves. The fraction which passed through the 40 mesh sieve but retained by the 10 mesh sieve was collected and used as solid substrate (particle size 0.177 to $0.420 \mathrm{~mm}$ ). All substrates were dried in an oven at $60^{\circ} \mathrm{C}$ for $24 \mathrm{~h}$. In $25 \times 150 \mathrm{~mm}$ test tube, $2 \mathrm{~g}$ of solid substrate thoroughly mixed with $2 \mathrm{ml}$ tap water (100\% initial moisture level) and autoclaved at $121{ }^{\circ} \mathrm{C}$ (15 psi) for $20 \mathrm{~min}$. After sterilization, there was no free flowing water present in all the tubes. The inoculums were prepared by growing $1 \mathrm{ml}$ spores suspension $\left(1 \times 10^{7}\right.$ spores $\left./ \mathrm{ml}\right)$ in $25 \mathrm{ml}$ YMG broth for $24 \mathrm{~h}$ under sterile condition. The sterilized initially $100 \%$ moistened $(\mathrm{v} / \mathrm{w})$ substrate was inoculated with $0.4 \mathrm{ml}$ of these inoculums ( $20 \% \mathrm{v} / \mathrm{w}$ of the initial dry substrate). The contents of the tubes were well mixed and incubated at $28^{\circ} \mathrm{C}$ in incubation chamber humidified by keeping distill water containing tray for various time periods. The substrate supporting the maximum production of avermectin was selected for further study.

\section{Moistening media}

Different moistening media, as reported in the literature for use with Streptomyces in SSF were tested (table 1). The avermectin production and biomass were analyzed in the fermented mass at $15^{\text {th }}$ days of incubation.

Table 1: Avermectin production and growth of S. avermitilis NRRL 8165 on sorghum with different moistening media in $15 \mathrm{~d}$ of incubation

\begin{tabular}{|c|c|c|c|}
\hline $\begin{array}{l}\text { Moistening } \\
\text { medium }\end{array}$ & Ingredients $\left(\mathrm{g} \mathrm{l}^{-1}\right)$ & $\begin{array}{l}\text { Avermectin } \\
\text { production }^{\text {a }}\end{array}$ & Biomass $^{\mathbf{b}}$ \\
\hline A & $\mathrm{KH}_{2} \mathrm{PO}_{4} 1 ; \mathrm{MgSO}_{4 .} 7 \mathrm{H}_{2} \mathrm{O}$ 0.4; $\mathrm{pH} 7$ [17] & $5.21 \pm 0.035$ & $141.12 \pm 3.21$ \\
\hline $\mathrm{B}$ & $\mathrm{KCl} 0.02 ; \mathrm{MgCl}_{2} 0.02 ; \mathrm{pH} 7[30]$ & $1.06 \pm 0.007$ & $52.45 \pm 1.51$ \\
\hline $\mathrm{C}$ & $\begin{array}{l}\mathrm{KH}_{2} \mathrm{PO}_{4} 5 ; \mathrm{NH}_{4} \mathrm{NO}_{3} 5, \mathrm{MgSO}_{4.7 \mathrm{H}_{2} \mathrm{O}} 1, \mathrm{NaCl} 1, \mathrm{CoCl}_{2} .6 \mathrm{H}_{2} \mathrm{O} 0.001, \mathrm{MnSO}_{4} .7 \mathrm{H}_{2} \mathrm{O} 0.0008, \\
\mathrm{ZnSO}_{4} .7 \mathrm{H}_{2} \mathrm{O} 0.0017, \mathrm{FeSO}_{4} .7 \mathrm{H}_{2} \mathrm{O} 0.0025, \mathrm{pH} 6.5[18]\end{array}$ & $3.91 \pm 0.049$ & $114.48 \pm 0.60$ \\
\hline $\mathrm{D}$ & $\mathrm{K}_{2} \mathrm{HPO}_{4} 5.3, \mathrm{NaHPO}_{4}$ 1.98, $\mathrm{MgSO}_{4} .7 \mathrm{H}_{2} \mathrm{O} 0.2, \mathrm{NaCl} 0.2, \mathrm{CaCl}_{2} .2 \mathrm{H}_{2} \mathrm{O} 0.02$ [19] & $2.82 \pm 0.280$ & $101.71 \pm 2.26$ \\
\hline $\mathrm{E}$ & $\mathrm{MgSO}_{4} .7 \mathrm{H}_{2} \mathrm{O} 0.01, \mathrm{KH}_{2} \mathrm{PO}_{4} 0.02 ; \mathrm{NH}_{4} \mathrm{NO}_{3} 0.05, \mathrm{NaCl} 0.01, \mathrm{pH} 7[20]$ & $4.30 \pm 0.120$ & $125.15 \pm 0.98$ \\
\hline
\end{tabular}

${ }^{a} \mathrm{mg} \mathrm{g}^{-1}$ dry substrate, ${ }^{\mathrm{b}} \mathrm{mg}$ dry biomass $\mathrm{g}^{-1}$ dry substrate, Values are the mean \pm standard error of 3 replicates

\section{Effect of $\mathrm{pH}$ of the moistening medium}

The effect of initial $\mathrm{pH}$ of the substrate on the production of avermectin was studied by varying the $\mathrm{pH}$ of moistening medium (Medium A) from $\mathrm{pH} 5.5-8.5$. The $\mathrm{pH}$ was adjusted with $0.1 \mathrm{~N}$ hydrochloric acid or $0.1 \mathrm{~N}$ sodium hydroxide. To measure post-sterilization $\mathrm{pH}, 1 \mathrm{~g}$ of the sterilized substrate was stirred in $10 \mathrm{ml}$ distilled water and $\mathrm{pH}$ was measured after settling the solid matter [13].

\section{Optimization of the culture conditions for avermectin production}

Different parameters to maximize the yield of avermectin by $S$. avermitilis NRRL 8165 under SSF were investigated. Parameter optimizes earlier was adopted during optimization of subsequent parameters. The effect of incubation temperature $\left(24-28{ }^{\circ} \mathrm{C}\right)$, initial moisture content (60-120\%), inoculums size $(5-25 \%)$ and substrate particle size on avermectin production was evaluated. The effect of additional carbon source (soluble starch, sucrose, maltose, glucose, molasses, lactose and fructose) all at $10 \% \mathrm{w} / \mathrm{w}$ and additional nitrogen source (organic nitrogen source-soyameal, peanut meal, peptone, malt extract and yeast extract at $5 \% \mathrm{w} / \mathrm{w}$, while inorganic nitrogen source$\left(\mathrm{NH}_{4}\right)_{2} \mathrm{SO}_{4}, \mathrm{KNO}_{3}, \mathrm{NaNO}_{3}$ and $\mathrm{NH}_{4} \mathrm{NO}_{3}$ at $0.5 \% \mathrm{w} / \mathrm{w}$ ) were studied.

\section{Extraction and analysis}

For avermectin extraction, $0.5 \mathrm{~g}$ of the fermented substrate was extracted with methanol $(5 \mathrm{ml})$ and the contents were agitated for 1 $\mathrm{h}$ at room temperature in a gyratory shaker at $150 \mathrm{rpm}$. The contents were centrifuged, and the pellet obtained was again mixed with another aliquot of $5 \mathrm{ml}$ of methanol, kept on a gyratory shaker overnight and subsequently centrifuged. The supernatants were pooled, volume made-up to $10 \mathrm{ml}$ and analyzed by HPLC method as described by Gao et al. [4] with some modifications. A C18 column (diameter $4.6 \times 250 \mathrm{~mm}$, length $284 \mathrm{~mm}$, particle size $5 \mu$ ) was developed with methanol-water $(85: 15)$ at a flow rate of $0.5 \mathrm{ml} \mathrm{min}$ ${ }^{1}$. The column temperature was set at $45{ }^{\circ} \mathrm{C}$ and products were monitored by UV detector at $245 \mathrm{~nm}$. The quantity of total avermectin was calculated from the integration value at $245 \mathrm{~nm}$ using an authentic sample of avermectin as a standard [14].

Table 2: Effect of initial pH of moistening media on selected parameters of sorghum, avermectin production and biomass accumulation of S. avermitilis NRRL 8165 in 15 d of incubation

\begin{tabular}{|c|c|c|c|c|}
\hline Moistening medium pH & Post-sterilization pH of substrate & Avermectin production ${ }^{b}$ & Biomass $^{c}$ & Reducing sugard \\
\hline 5.5 & $6.86 \pm 0.12$ & $4.90 \pm 0.08$ & $131.2 \pm 4.20$ & $2.47 \pm 0.040$ \\
\hline 6 & $6.87 \pm 0.15$ & $4.88 \pm 0.05$ & $134.2 \pm 3.80$ & $1.92 \pm 0.113$ \\
\hline 6.5 & $6.89 \pm 0.09$ & $4.78 \pm 0.07$ & $129.5 \pm 2.11$ & $1.69 \pm 0.125$ \\
\hline 7 & $6.89 \pm 0.08$ & $4.96 \pm 0.040$ & $132.3 \pm 4.36$ & $1.61 \pm 0.040$ \\
\hline 7.5 & $6.88 \pm 0.15$ & $4.92 \pm 0.035$ & $134.8 \pm 4.11$ & $1.68 \pm 0.025$ \\
\hline 8 & $7.00 \pm 0.12$ & $5.01 \pm 0.045$ & $129.9 \pm 5.30$ & $1.34 \pm 0.030$ \\
\hline 8.5 & $7.57 \pm 0.10$ & $4.93 \pm 0.069$ & $129.8 \pm 2.69$ & $1.58 \pm 0.049$ \\
\hline
\end{tabular}

a1 g of sterilized substrate was stirred in $10 \mathrm{ml}$ distilled water and pH was measured after settling the solid matter, $\mathbf{b}$ mg g-1 dry substrate, ${ }^{\mathbf{c}}$ mg dry biomass per gram of dry substrate, ${ }^{\mathbf{d}}$ reducing sugar released from sorghum after autoclaving in mg g-1 wet substrate, Values are the mean \pm standard error of 3 replicates.

\section{Biomass estimation}

Biomass accumulated during the fermentation was estimated by the method reported by Kagliwal et al. [13]. A standard curve was prepared using $\mathrm{N}$-acetyl glucosamine as standard $\left(\mathrm{R}^{2}=0.997\right)$ and was correlated to dry biomass of $S$. avermitilis NRRL 8165 grown in liquid culture $\left(R^{2}=0.991\right)$. Biomass has been represented as mg dry biomass per gram of dry substrate $\left(\mathrm{mg} \mathrm{db} \mathrm{g}^{-1} \mathrm{dsb}\right)$.

\section{Reducing sugar estimation of substrate}

For analysis of reducing sugar released during autoclaving, $20 \mathrm{ml}$ distilled water was added in $2 \mathrm{~g}$ of the autoclaved substrate and kept on a gyratory shaker at $180 \mathrm{rpm}$ for an hour. The Clear solution was separated from the substrate and the amount of reducing sugar released from substrate was determined by DNS method [15].

\section{Statistical analysis}

Statistical analyses were performed using GraphPad Prism version 5.00 for Windows, GraphPad Software, San Diego California USA. Student's t-test was employed to investigate statistical differences and $\mathrm{P}<0.05$ was considered significant. Unless otherwise indicated, all values were the means of three independent trials \pm standard deviations. No significant differences were observed between individual replicates. Pearson's correlation coefficient (r) and regression coefficient $\left(\mathrm{R}^{2}\right)$ were also calculated. 


\section{RESULTS}

\section{Evaluation of various substrates for avermectin production}

Different solid substrates viz. wheat bran, wheat rawa, sorghum, amaranth, pearl millet, barley, maize, potato and sawdust were screened for production of avermectin by $S$. avermitilis NRRL 8165. Five substrates were found to be capable of supporting the growth and production of avermectin. Fig. 1 shows the time course of avermectin production and biomass accumulation of these substrates. Sorghum was found to be the best substrate giving a maximum production of $4.4 \pm 0.02 \mathrm{mg} \mathrm{g}^{-1} \mathrm{dsb}$ (dry substrate basis) followed by wheat rawa, pearl millet and amaranth at $15 \mathrm{~d}$. Rice gave the lowest production of avermectin $\left(2.35 \pm 0.063 \mathrm{mg} \mathrm{g}^{-1} \mathrm{dsb}\right)$ in same period of incubation. Further incubation did not show any significant increment in antibiotic production (fig. 1a). Sorghum also supported maximum biomass of $133.63 \pm 3.73 \mathrm{mg}$ of db (dry biomass) $\mathrm{g}^{-1}$ of dsb at $15 \mathrm{~d}$. Amaranth, rice and pearl millet also showed growth of $111.68 \pm 5.59,83.71 \pm 3.62$, and $97.21 \pm 3.51 \mathrm{mg}$ of $\mathrm{db} \mathrm{g}^{-1} \mathrm{of} \mathrm{dsb}$, respectively at $15 \mathrm{~d}$. Wheat rawa produced maximum biomass at $20 \mathrm{~d}\left(99.66 \pm 13.8 \mathrm{mg}\right.$ of $\mathrm{db} \mathrm{g}^{-1}$ of dsb) (fig. 1b), and further incubation after $20 \mathrm{~d}$ did not show increment in biomass (data not shown).

\section{Optimization of process parameters}

Among the five different moistening media tested Medium A showed maximum production of avermectin $\left(5.2 \mathrm{mg} \mathrm{g}^{-1} \mathrm{dsb}\right)$ as well as biomass accumulation as compared to other moistening media (table 1). The effect of initial $\mathrm{pH}$ levels (5.5-8.5) of medium A on avermectin production during SSF was evaluated (table 2). Initial $\mathrm{pH}$ of moistening medium does not show a significant effect on biomass accumulation and avermectin production. To evaluate the effect of initial $\mathrm{pH}$ on sorghum post-sterilization $\mathrm{pH}$ and reducing sugar content were measured. After sterilization, substrate $\mathrm{pH}$ and reducing sugar released during autoclaving did not show significant change along with different initial $\mathrm{pH}$ value of moistening medium (table 2). Also at the end of the fermentation $\mathrm{pH}$ of all tested variables did not change. Temperature affects microbial growth, spore formation, germination and microbial physiology, thus affecting product formation. Analysis of avermectin production revealed that maximum yield $\left(5.40 \pm 0.156 \mathrm{mg} \mathrm{g}^{-1} \mathrm{dsb}\right)$ is recorded at $28^{\circ} \mathrm{C}$ (fig. 2). Reduced avermectin production was observed at higher or lower incubation temperatures. Fig. 2 represent the effect of inoculums level on avermectin production by S. avermitilis NRRL 8165 on sorghum. Progressive increases in product yield are observed with increase in inoculums from 5 to $20 \%$ of the initial dry substrate and after that product yield slightly decrease. Maximum avermectin production of $5.40 \pm 0.175 \mathrm{mg} \mathrm{g}^{-1} \mathrm{dsb}$ was observed with $20 \%$ inoculums level in $15 \mathrm{~d}$.

\section{(a)}

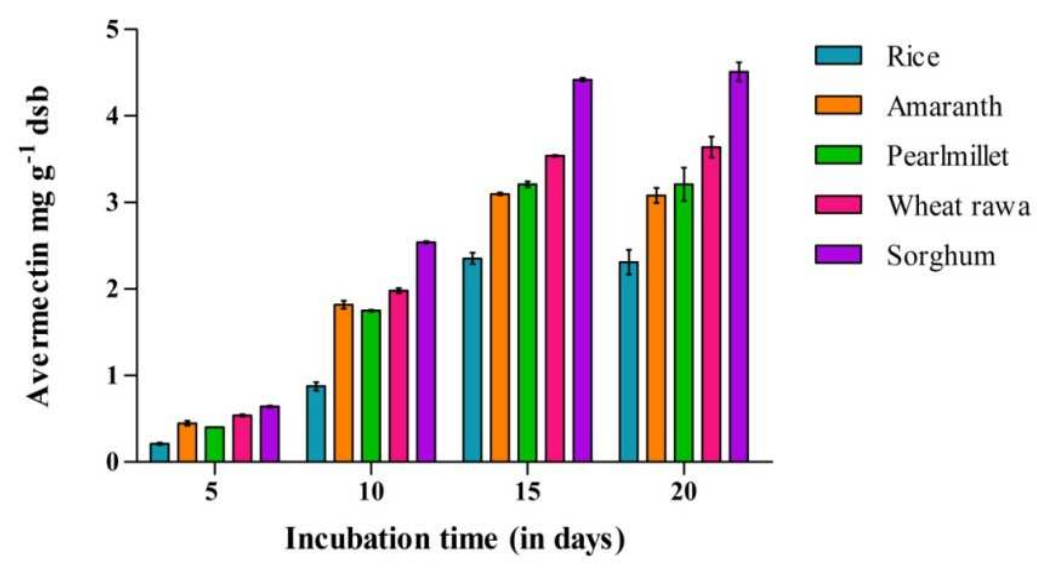

(b)

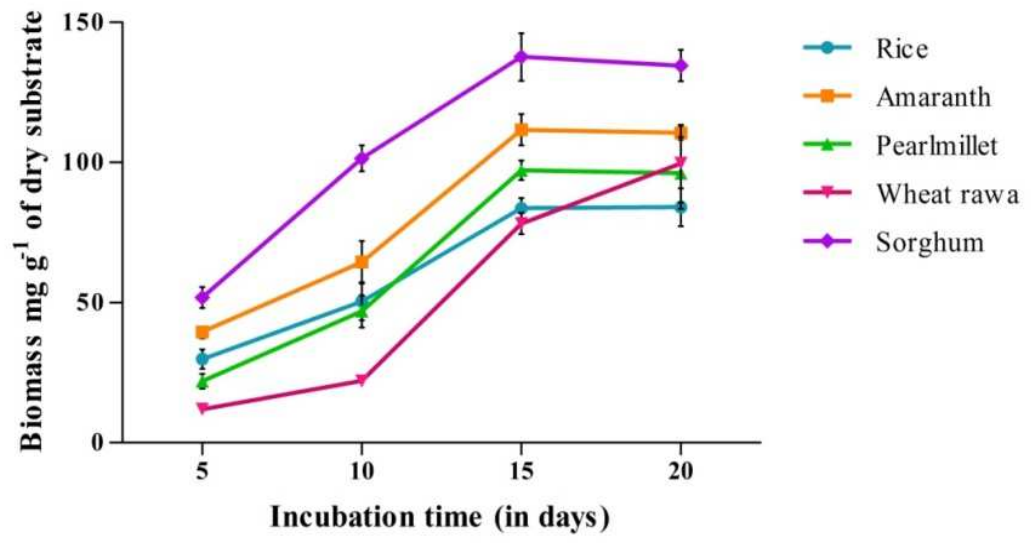

Fig. 1: Avermectin production and growth profile of $S$. avermitilis NRRL 8165 on solid substrates. (a) Represent avermectin production, (b) Represent biomass accumulation of $S$. avermitilis NRRL 8165 on different solid substrates. Initial moisture content $100 \%$, inoculums level $20 \% \mathrm{v} / \mathrm{w}$, incubation temperature $28{ }^{\circ} \mathrm{C}$, incubation time $15 \mathrm{~d}$. Values are the mean \pm standard error of 3 replicates 
Temperature $\left({ }^{\circ} \mathrm{C}\right)$

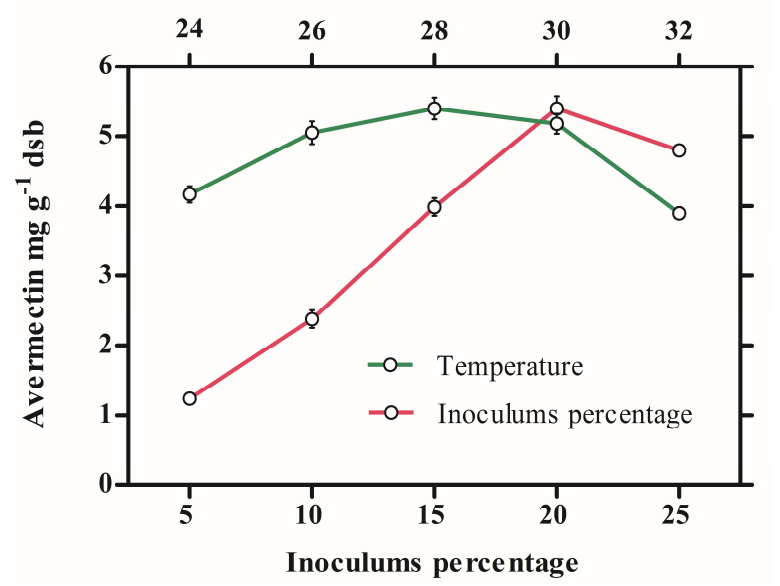

Fig. 2: Avermecin production at selected inoculums level and temperature range by $S$. avermitilis NRRL 8165. Initial moisture content $100 \%$, incubation time $15 \mathrm{~d}$. Values are the mean \pm standard error of 3 replicates

The effect of initial moisture contents of the substrate (sorghum) on avermectin production is given in fig. 3 . The result indicated that the maximum yield of avermectin $\left(5.55 \pm 0.214 \mathrm{mg} \mathrm{g}^{-1} \mathrm{dsb}\right)$ was obtained from $105 \%$ initial moisture and a further increase in moisture levels reduced the avermectin content. After the fermentation, all the tubes with different initial moisture levels were showed relatively same final moisture content. At low moisture content, avermectin accumulation reduced because the water content was not sufficient enough for growth and metabolic activities. The experimental data revealed that avermectin production was affected by the particle size. Maximum avermectin production $\left(5.61 \pm 0.210 \mathrm{mg} \mathrm{g}^{-1} \mathrm{dsb}\right)$ was recorded with mixed size ( 0.5 to $4 \mathrm{~mm}$ ) sorghum particles when initial moisture content was $105 \%$ (fig. 3).

The impact of supplementation of external carbon sources on avermectin production was studied and the results have shown 20 $\%$ improvement in the avermectin production with sucrose and 12 $\%$ with maltose (both at $10 \% \mathrm{w} / \mathrm{w}$ ) (fig. 4). A marginal non significant improvement was observed with lactose. However, more than $35 \%$ reduced avermectin production was noticed with the supplementation of soluble starch suggesting that this carbon source could be a repressor of avermectin production in SSF. Glucose, fructose and molasses showed a slightly reduction in avermectin production. To determine the optimum sugar level, different concentrations of sucrose was supplemented in the range (6-14\% $\mathrm{w} / \mathrm{w})$. Maximum production (5.61 $\mathrm{mg} \mathrm{g}^{-1} \mathrm{dsb}$ ) was observed with 8 $\%$ sucrose concentration (fig. 4). Increase in the concentration of sucrose beyond this adversely affected avermectin production. The effect of different nitrogen sources on avermectin production by $S$. avermitilis NRRL 8165 was studied at optimized SSF environment (fig. 5). Results revealed that among selected nitrogen sources, soyameal at a given concentration $(5 \% \mathrm{w} / \mathrm{w})$ showed highest antibiotic production, while all other nitrogen sources resulted in decrease production of antibiotic compare to control (fig. 5). Further evaluation of soyameal concentration showed a parabolic nature of production pattern indicating that this nitrogen source play a critical role on avermectin production (fig. 5).

\section{DISCUSSION}

SSF has become an interesting alternative for the production of secondary metabolites since the metabolites are more concentrated, more stable and their downstream processing are easy as well as less costly [16]. There are several factors which affect the SSF processes, among these; selection of suitable substrate is crucial [9]. The solid substrates not only supply the nutrients for growth of microorganism, but also serve as an anchorage for the cell. Since no substrate was reported for production of avermectin using SSF.
Moisture percentage $(v / w)$

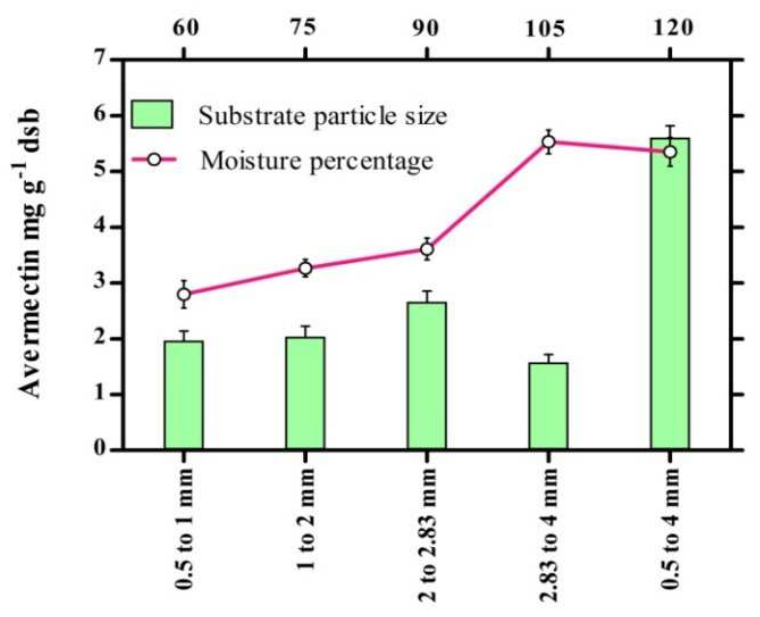

Substrate particle size

Fig. 3: Avermectin production at selected substrate particle size and moisture levels by $S$. avermitilis NRRL 8165. Inoculums level $20 \% \mathrm{v} / \mathrm{w}$, incubation temperature $28^{\circ} \mathrm{C}$, incubation time $15 \mathrm{~d}$. Values are the mean \pm standard error of 3 replicates

Different types of solid substrate were used for avermectin production in SSF. Among the tested substrates, five substrates (sorghum, amaranth, pearl millet, rice and wheat rawa) were supported avermectin production and growth of $S$. avermitilis (fig. 1). Sorghum supported maximum growth and avermectin production as compared to other substrates. Substrate-dependent variations in production of metabolites were also reported in the literature [17-22].

Production profile and growth curve of S. avermitilis NRRL 8165 on different substrates showed a positive correlation between growth and secondary metabolite production $\left(\mathrm{r}=0.9941 ; \mathrm{R}^{2}=0.9883\right)$. The possible reason for the reduced avermectin accumulation and growth on wheat rawa and rice could be attributed to the formation of aggregates, limiting the growth of microorganism by reducing surface area. Based on the above results, sorghum was found to be most suited amongst the tested substrates for growth and avermectin production by $S$. avermitilis NRRL 8165. In SSF, sorghum has been widely used for ethanol and organic acid production [8]. Sorghum contains $72.09 \%$ carbohydrate, $10.62 \%$ proteins, $6.7 \%$ fibers, $3.46 \%$ fatty acids, $2.53 \%$ sugars, various minerals and vitamins [23]. It works as solid substrate and also contains all the components that could support growth of S. avermitilis NRRL 8165. However, this work apparently is the first report regarding use of sorghum for secondary metabolite production.

Medium A supported maximum biomass as well as avermectin production by this strain. Vastral and Neelagund [17] have reported this medium A for production of neomycin by Streptomyces fradiae NCIM 218. Many processes (ATP, DNA and RNA synthesis) occurring in the living system requires phosphorus [24]. Magnesium works as a cofactor of the enzymes involved in protein synthesis [25]. Ababutain et al. [26] reported that salt of magnesium and potassium are the most appropriate for growth and secondary metabolite production by Streptomyces species. Medium $\mathrm{C}$ and E containing $\mathrm{NH}_{4} \mathrm{NO}_{3}$ led to relatively low levels of avermectin and biomass in the present case. Khaliq et al. [21] also reported the inhibitory effect of ammonium ion on tylosin production in SSF by Streptomyces fradiae NRRL 2702.

In most of the fermentation, the control of $\mathrm{pH}$ of the medium at optimum level is essential for achieving maximum product. Reports on secondary metabolite production under SSF showed a significant effect of initial $\mathrm{pH}$ of moistening medium on antibiotic production $[13,17,19-22]$, but in this study $\mathrm{pH}$ of moistening medium did not show any effect in biomass and avermectin production (table 2). This may be attributed to the fact that sorghum has high buffering 
capacity which resists change in $\mathrm{pH}$ as well as other tested parameters. Irrespective of type of fermentation, sizes of inoculum affect the formation of final product. As shown in fig. 2, optimum inoculums level was $20 \%$ for the avermectin production. Lower and higher inoculums level than the optimum resulted in decreased avermectin production. The Higher amount of inoculums may cause quick and too much biomass production thereby leading to fast nutrient depletion and ultimately reduce secondary metabolite synthesis. A low inoculums density leads to insufficient biomass and end product synthesis [21].
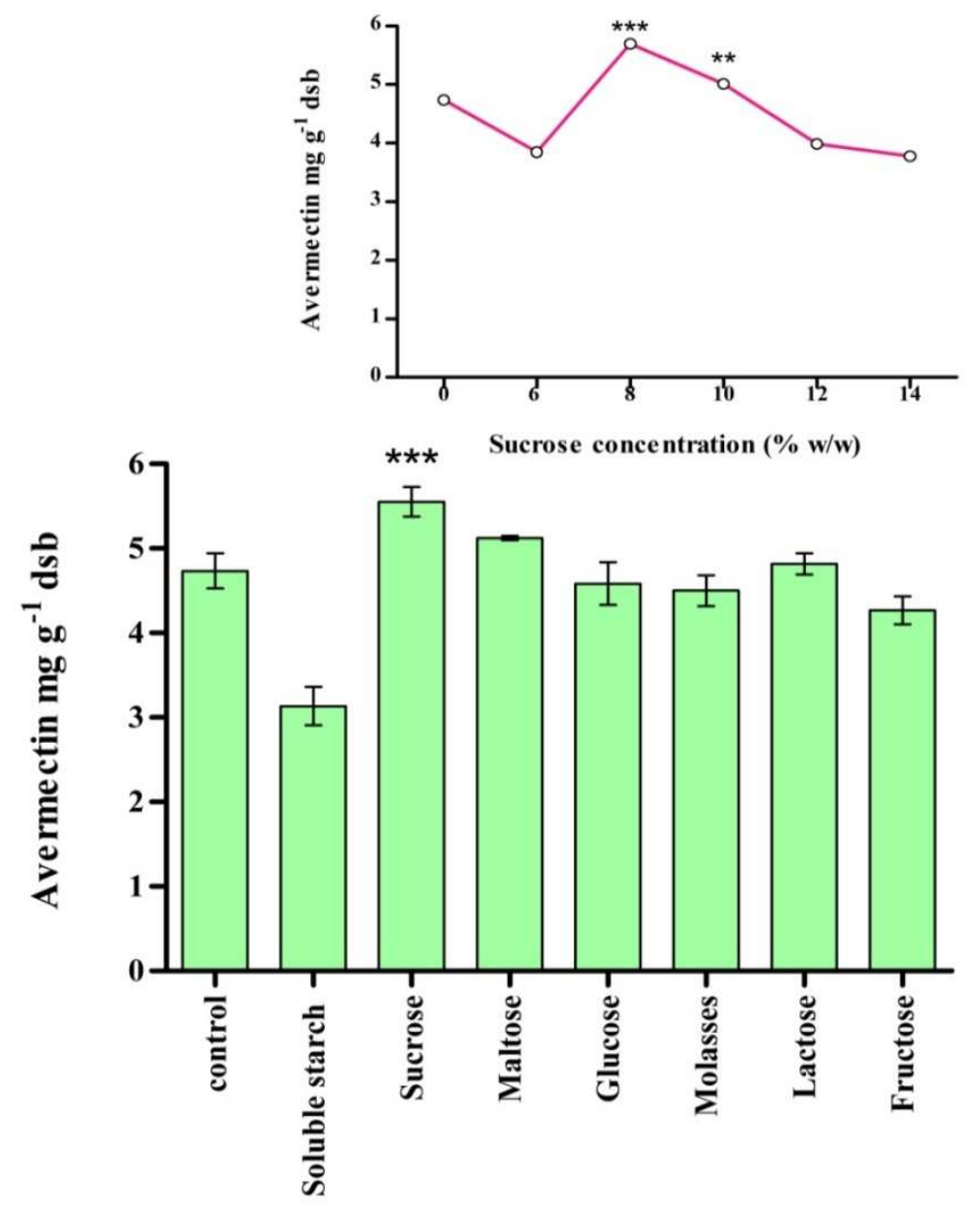

Carbon Sources $(10 \% \mathrm{w} / \mathrm{w})$

Fig. 4: Evaluation of carbon addition effect on avermectin production by $S$. avermitilis NRRL 8165 under SSF with sorghum as substrate (control: only sorghum). Inset effect of different concentration of sucrose. ${ }^{*} \mathrm{P}<0.05$; ${ }^{* *} \mathrm{P}<0.01$; ${ }^{* * *} \mathrm{P}<0.005$ variable vs control (student's $\mathrm{t}$ test)

In case of SSF, the Moisture level is one of the imported factor that affects growth and production of desire product [27]. The highest avermectin production was obtained at $105 \%$ initial moisture contents (fig. 3). Low moisture decreased the availability of nutrients thus lowering the growth and finally reduces the production of secondary metabolites [28]. Under higher moisture level substrate porosity decreased which reduced mass transfer [29]. Similar observations were noticed in the literature [20, 22, 30] during SSF studies carried out for other metabolites.

Substrate particle size is a crucial factor in SSF process. Small particle sizes provide larger surface area for growth but decrease interparticle porosity. Larger particle size decrease surface area, limit nutrient transfer and increase interparticle space with suitable respiration and aeration characteristics. The particles sizes (0.5-4 $\mathrm{mm}$ ) of the substrate were found to be optimal size of the substrate for maximum avermectin production (fig. 3). Data suggest that selection of substrate particle size is one of the essential requirements for production optimization in SSF $[17,22]$.

In solid substrate, some of the important nutrients necessary for growth and secondary metabolite synthesis for microorganism may also be present at sub-optimal level. Hence, the addition of other nutrients may improve product formation in SSF processes. $S$ avermitilis NRRL 8165 can grow and produce avermectin on sorghum, but the organism may needed additional carbon source for maximum secondary metabolite synthesis. Different carbon sources were supplemented to solid substrate at $10 \%(\mathrm{w} / \mathrm{w})$. Results showed disaccharides supported, while monosaccharide's decreased avermectin production (fig. 4). Readily available carbon sources like glucose, fructose and molasses were reported to work as a repressor for enzymes which are involved in the synthesis of secondary metabolites [21]. Asagbra et al. [31] also reported the stimulatory effect of disaccharides in secondary metabolism. In SSF environment organism suffer from osmotic stress and synthesized solutes responsible for osmoregulation called compatible solutes. Sucrose is used as one of the compounds to reduce osmotic stress. Elibol [32] reported sucrose might also act as an enzyme system inducer responsible for the synthesis of a polyketide antibiotic actinorhodin produced by Streptomyces coelicular A3 (2). Yang and ling [33] also reported stimulatory effect of sucrose on tetracycline production with sweet potato residue by Streptomyces viridiciens ATCC 11989 under SSF. A similar observation was also reported in pikromycin production by Streptomyces venezuelae ATCC 15439. An optimum concentration of sucrose (139 $\left.\mathrm{g} \mathrm{l}^{-1}\right)$ was required for pikromycin production [34]. 


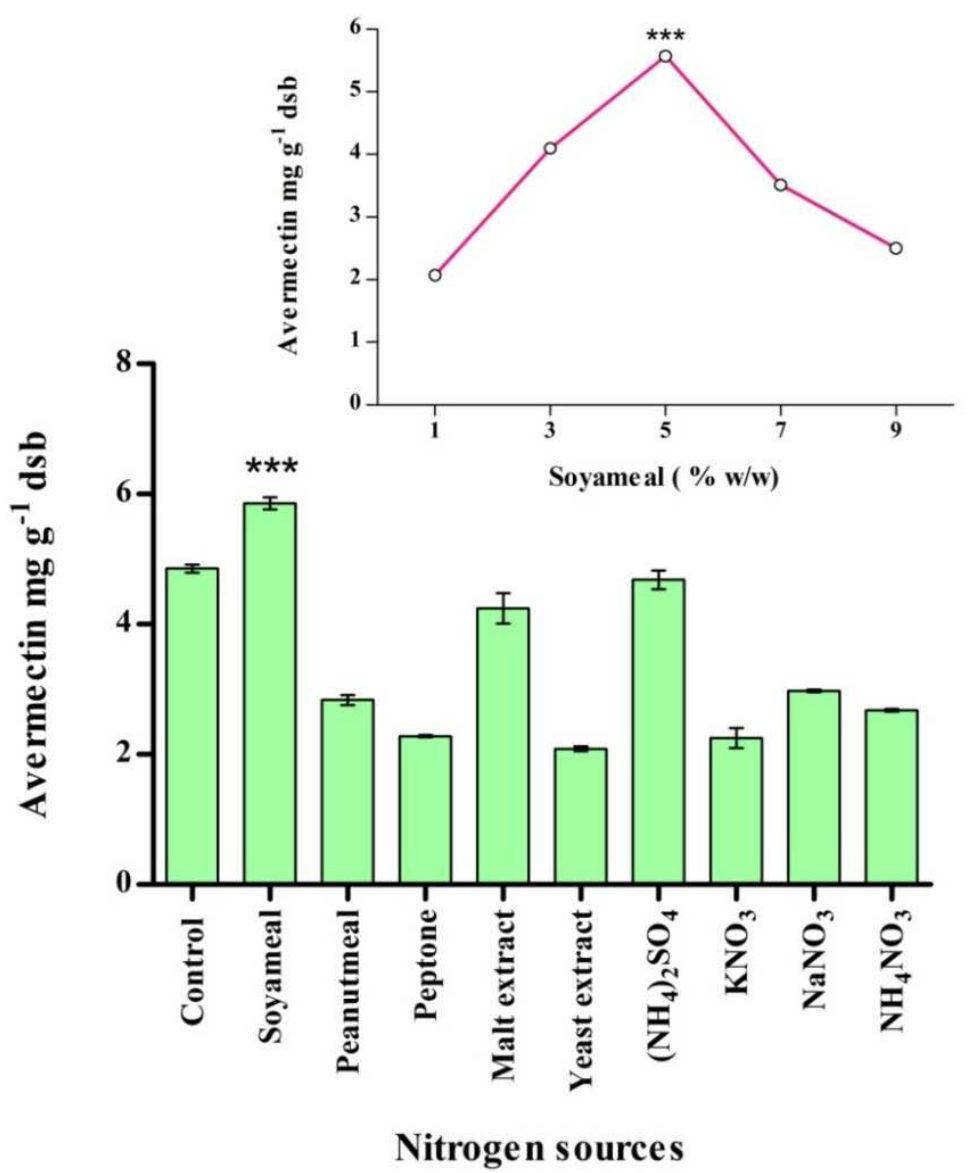

Fig. 5: Screening of different nitrogen sources avermectin production by $S$. avermitilis NRRL 8165 on sorghum. Inset effect of different concentration of soyameal. ${ }^{*} \mathrm{P}<0.05 ;{ }^{* *} \mathrm{P}<0.01 ;{ }^{* * *} \mathrm{P}<0.005$ variable vs control (student's t test), organic nitrogen source - soya meal, peanut meal, peptone, malt extract and yeast extract at $5 \% \mathrm{w} / \mathrm{w}$, while inorganic nitrogen source -(NH4)2SO4, KNO3, NaNO3 and NH4NO3 at $0.5 \% \mathrm{w} / \mathrm{w}$

Soyameal is complex, cheap and commercially available nitrogen sources and has advantage of slow breakdown during the fermentation. Addition of soyameal (at $5 \% \mathrm{w} / \mathrm{w}$ ) has a positive effect on avermectin biosynthesis under SSF (fig. 4). When different concentration of soyameal $(1-9 \% \mathrm{w} / \mathrm{w})$ was added, it showed a parabolic graph of avermectin production (fig. 4). Li et al. [35] reported soyameal is the best nitrogen source for streptolydign A production by Streptomyces lydicus AS 4.2501. Bhavna et al. reported that maximum growth and antimicrobial compound production by Streptomyces carpaticus MTCC 11062 required an optimum concentration of soyameal [36]. Mahalaxmi et al. [22] also reported a critical role of soyameal in rifamycin B production by Amycolatopsis sp RSP 3 under SSF. In the present study with the optimum fermentation conditions, maximum avermectin production $(5.8 \mathrm{mg}$ $\mathrm{g}^{-1} \mathrm{dsb}$ ) was recorded in $15 \mathrm{~d}$ of incubation.

\section{CONCLUSION}

Present work represents the first report of avermectin production by $S$. avermitilis in SSF condition. Maximum avermectin production was recorded with sorghum as a substrate. Initial $\mathrm{pH}$ of moistening medium does not affect the biomass and avermectin production on sorghum in the tested range. The identified and optimized process parameters include $105 \%$ initial moisture content, $20 \%(\mathrm{v} / \mathrm{w})$ inoculums, incubation at $28{ }^{\circ} \mathrm{C}$, incubation time $15 \mathrm{~d}, 8 \%$ sucrose $(\mathrm{w} / \mathrm{w})$ and $5 \%(\mathrm{w} / \mathrm{w})$ soyameal. Under the optimal condition, the avermectin production of $5.8 \mathrm{mg} \mathrm{g}^{-1} \mathrm{dsb}$ has achieved an approximated 1.3 fold improvement over initial yield $(4.42 \mathrm{mg} \mathrm{g}$ ${ }^{1} \mathrm{dsb}$ ) with non-optimized conditions. It was reported that under SmF condition S. avermitilis NRRL 8165 (ATCC 31267) produce $0.175 \mathrm{mg} \mathrm{ml}^{-1}$ avermectin [37], while in optimized SSF condition this strain produces $5.8 \mathrm{mg} \mathrm{g}^{-1} \mathrm{dsb}$ avermectin. In future SSF process for avermectin can become an alternative to classical submerged fermentation.

\section{ACKNOWLEDGEMENT}

Shadab Khan thanks, Council of Scientific and Industrial Research (CSIR), India for Senior Research Fellowship [09/301/(0124)/ 2012/EMR-I].

\section{AUTHORS CONTRIBUTION}

All authors contributed equally

\section{CONFLICT OF INTERESTS}

The authors declare that they have no conflict of interest in the publication

\section{REFERENCES}

1. Burg RW, Miller BM, Baker EE, Birnbaum J, Currie S, Hartman $\mathrm{R}$, et al. Avermectins, new family of potent anthelmintic agents: producing organisms and fermentation. Antimicrob Agents Chemother 1979;15:361-7.

2. Egerton JR, Ostling DA, Blair LS, Eary CH, Suhayda D, Cifelli S, et al. Avermectins, new family of potent anthelmintic agents: efficacy of the B1a component. Antimicrob Agents Chemother 1979;15:372-8.

3. Lim LE, Vilcheze C, Ng C, Jacobs WR Jr, Ramon-Garcia S, Thompson CJ. Anthelmintic avermectins kill Mycobacterium tuberculosis, including multidrug-resistant clinical strains. Antimicrob Agents Chemother 2013;57:1040-6.

4. Gao H, Liu M, Liu J, Dai H, Zhou, Liu X, et al. Medium optimization for the production of avermectin B1a by 
Streptomyces avermitilis 14-12 using response surface methodology. Bioresour Technol 2009;100:4012-6.

5. Thuan NH, Pandey RP, Sohng JK. Recent advances in biochemistry and biotechnological synthesis of avermectins and their derivatives. Appl Microbiol Biotechnol 2014;98:7747-59.

6. Chen W, He F, Zhang X, Chen Z, Wen Y, Li J. Chromosomal instability in Streptomyces avermitilis: major deletion in the central region and stable circularized chromosome. BMC Microbiol 2010;10:198.

7. Novak J, Kopecky J, Kofronova O, Vanek Z. Instability of production of avermectins, sporulation and pigmentation in Streptomyces avermitilis. Can J Microbiol 1993;39:265-7.

8. Xu ZQ, Feng XH, Zhang D, Tang B, Lei $\mathrm{P}, \mathrm{Xu} H$. Enhanced poly (gammaglutamic acid) fermentation by Bacillus subtilis NX-2 immobilized in an aerobic plant fibrous-bed bioreactor. Bioresour Technol 2014;155:8-14.

9. Pandey A, Soccol CR, Mitchell D. New developments in solidstate fermentation, I-bio-processes and applications. Process Biochem 2000;35:1153-69.

10. Pandey A. Solid-state fermentation. Biochem Eng J 2003;13:81-4.

11. Barrios-González J. Solid-state fermentation: physiology of solid medium, its molecular basis and applications. Process Biochem 2012;47:175-85.

12. Kennedy M, Krouse D. Strategies for improving fermentation medium performance: a review. J Indian Microbiol Biotechnol 1999;23:456-75.

13. Kagliwal LD, Survase SA, Singhal RS. A novel medium for the production of cephamycin C by Nocardia lactamdurans using solid-state fermentation. Bioresour Technol 2009;100:2600-6.

14. Curdova E, Jechova V, Zima J, Vanek Z. The effect of inorganic phosphate on the production of avermectin in Streptomyces avermitilis. J Basic Microbiol 1989;29:341-6.

15. Miller GL. Use of dinitrosalicylic acid reagent for determination of reducing sugar. Anal Chem 1959;31:426-8.

16. Robinson T, Singh D, Nigam P. Solid state fermentation: a promising microbial technology for secondary metabolite production. Appl Microbial Biotechnol 2001;55:284-9.

17. Vastrad BM, Neelagund SE. Optimization and production of neomycin from different agro industrial wastes in solid state fermentation. Int J Pharma Sci Drug Res 2011;2:104-10.

18. Nagy V, Szakacs G. Production of transglutaminase by Streptomyces isolates in solid-state fermentation. Lett Appl Microbiol 2008;47:122-7.

19. Alberton LR, Vandenberghe LPS, Assman R, Fendrich RC, Rodriguéz-León J, Soccol CR. Xylanase production by Streptomyces viridosporus T7A in submerged and solid-state fermentation using agro-industrial residues. Braz Arch Biol Technol 2009;52:171-80.

20. Bussari B, Saudagar PS, Shaligram NS, Survase SA, Singhal RS. Production of cephamycin C by Streptomyces clavuligerus NT4 using solid state fermentation. J Ind Microbiol Biotechnol 2008;35:49-58.

21. Khaliq S, Rashid N, Akhtar K, Ghauri MA. Production of tylosin in solid state fermentation by Streptomyces fradiae NRRL-2702 and its gamma irradiated mutant $(\gamma-1)$. Lett Appl Microbiol 2009;49:635-40.

22. Mahalaxmi Y, Sathish T, Subba Rao C, Prakasham RS. Corn husk as a novel substrate for the production of rifamycin $\mathrm{B}$ by isolated Amycolatopsis sp. RSP 3 under SSF. Process Biochem 2010;45:47-53.

23. Nutrient data laboratory. Available from: http://ndb.nal.usda.gov/ndb/search/list. United States Department of Agriculture. [Last accessed on 10 May 2016]

24. Prokofieva-Belgovskaya A, Popova L. The influence of phosphorus on the development of Streptomyces aureofaciens and on its ability to produce chlortetracycline. J Gen Microbiol 1959;20:462-72.

25. Wolf FI, Cittadini A. Magnesium in cell proliferation and differentiation. Front Biosci 1999;4:607-17.

26. Ababutain IM, Aziz ZKA, AL-Meshhen NA. Optimization of environmental and nutritional conditions to improve growth and antibiotic productions by Streptomyces Sp. Isolated from Saudi Arabia Soil. Int Res J Microbiol 2013;4:179-87.

27. Raimbault M. General and microbiological aspects of solid substrate fermentation. Egypt J Biotechnol 1998;1:174-88.

28. Carrizales V, Rodrigues H, Sardina I. Determination of specific growth rate of molds as semisolid cultures. Biotech Bioeng 1981;232:321-33.

29. Martins S, Mussatto SI, Martinez-Avila G, Montanez-Saenz J, Aguilar CN, Teixeira JA. Bioactive phenolic compounds: production and extraction by solid-state fermentation. A review. Biotechnol Adv 2011;29:365-73.

30. Li QS, Xu JJ, Zhong JJ. Production of L-glutamate oxidase and in situ monitoring of oxygen uptake in solid state fermentation of Streptomyces sp. N1. Appl Biochem Biotechnol 1997;62:243-50.

31. Asagbra EA, Sanni IA, Oyewolen BO. Solid state fermentation production of tetracycline by Streptomyces strains using some agricultural wastes as substrate. W J Microbiol Biotech 2005;21:107-14.

32. Elibol M. Optimization of medium composition for actinorhodin production by Streptomyces coelicolorA3 with response surface methodology. Process Biochem 2004;39:1057-62.

33. Yang SS, Ling MY. Tetracycline production with sweet potato residues by solid-state fermentation. Biotechnol Bioeng 1989;33:1021-8.

34. Yi JS, Kim M, Kim SJ, Kim BG. Effects of sucrose, phosphate, and calcium carbonate on the production of pikromycin from Streptomyces venezuelae. J Microbiol Biotechnol 2015;25:496-502.

35. Li LZ, Qiao B, Yuan Y. Nitrogen sources affect streptolydigin production and related secondary metabolites distribution of Streptomyces lydicus AS 4.2501. Chin J Chem Eng 2007;15:403-10.

36. Bhavana M, Talluri VP, Kumar KS, Rajagopal SV. Optimization of culture conditions of Streptomyces carpaticus (MTCC-11062) for the production of antimicrobial compound. Int J Pharm Pharm Sci 2014;6:281-5.

37. Li M, Chen Z, Zhang X, Song Y, Wen Y, Li J. Enhancement of avermectin and ivermectin production by overexpression of the maltose ATP-binding cassette transporter in Streptomyces avermitilis. Bioresour Technol 2010;101:9228-35.

\section{How to cite this article}

- Shadab Khan, Pushpendra Awadhiya, Shridhar Patil, Tushar Banerjee. Avermectin production by solid state fermentation-a novel approach. Int J Pharm Pharm Sci 2017;9(10):55-61. 